УДК 165

DOI 10.18413/2712-746X-2020-45-1-59-68

\title{
КОНЦЕПТ И ПРОБЛЕМА ПЕРЕВОДА
}

\section{CONCEPT AND THE PROBLEM OF TRANSLATION}

\author{
А.И. Швырков ${ }^{1}$, Д.М. Кошлаков ${ }^{1,2}$ \\ A.I. Shvyrkov ${ }^{1}$, D.M. Koshlakov ${ }^{1,2}$ \\ Брянский государственный технический университет ${ }^{1}$, \\ Россия, 241035, г. Брянск, б-р 50 лет Октября, 7; \\ Институт философии $\mathrm{PAH}^{2}$, \\ Россия, 109240, г. Москва, ул. Гончарная, д. 12, стр. 1. \\ Bryansk State Technical University ${ }^{1}$ \\ 7, 50 let Oktyabrya Boulevard, Bryansk, 241035, Russia; \\ RAS Institute of Philosophy', \\ 12, str. 1 Goncharnaya St, Moscow, 109240, Russia \\ E-mail: aishvyrkov@rambler.ru; dmkosh2012@yandex.ru
}

\begin{abstract}
Аннотация
Дан анализ некоего механизма мышления, приходящего в действие в случае заимствования иностранных научных (философских) терминов. Поскольку практически любое иностранное слово заучивается не с одним основным значением, а с несколькими близкими, то данное слово оказывается не просто одним из нескольких синонимов, а как бы вбирает в себя смысл их всех. В результате часто смысл слова в той литературе, для которой оно является заимствованным, оказывается отличным от смысла этого слова в литературе на том языке, из которого оно было заимствовано. Данный механизм, однако, далеко не всегда является проблемой - наоборот, часто его действие позволяет обогатить аппарат науки и философии. Но в этом случае возникает необходимость в «обратном переводе» заимствованного термина - переводе, который бы позволил донести до иностранного читателя те смыслы, которые в «родных» для данного термина языках либо остаются не актуализированными, четко не артикулированными, либо не связываются со специальным термином. На данную проблематику авторы вышли в результате анализа термина «концепт», сравнительно недавно вошедшего в российский научный и философский оборот. Поэтому в статье также рассматривается история использования понятия концепта от Средневековья до наших дней, анализируются различные значения, в которых соответствующий термин употребляется в философии и науке. Делается попытка показать, что в отечественной литературе понятие концепта часто может приобретать несколько иной смысл, чем он имеет в европейской (в том числе и благодаря действию описанного механизма).
\end{abstract}

\section{Summary}

The article analyzes a certain mechanism of thinking that comes into effect in the case of borrowing foreign scientific (philosophical) terms. The essence of this mechanism is follows. Almost every foreign word is memorized not with one basic meaning but with several close ones. Due to this, this word is not just one of several synonyms. It absorbs all them. The result can often be that the meaning of a word in the literature for which it is borrowed turns out to be different from the meaning of the word in literature in the language from which it was borrowed. This mechanism, however, is far from always being a problem. On the contrary, its action often allows us to enrich the apparatus of science and philosophy. Though in this case it is probably necessary to make a "reverse translation" of the loaned term, i.e. a translation which allows conveying to foreign readers meanings which in the "native" for the term languages are either not clearly articulated not associated with a special term. The authors came to this issue as a result of the analysis of the term "concept" which recently entered Russian scientific and philosophical circulation. That's why the article also examines the history of the use of the term from the Middle Ages to the present day, analyzes various meanings in which the corresponding term is used in 
philosophy and science. An attempt is made to show that in Russian literature the term can often acquire a slightly different meaning than it has in European literature (partly due to the action of the mechanism described).

Ключевые слова: концепт, концептуализм, обратный перевод, смысл, термин.

Keywords: concept, conceptualism, reverse translation, meaning, term.

\section{Введение}

Значительное количество специальных терминов, используемых в научных и философских трудах, написанных на русском языке, имеют иностранное происхождение. Хотя в русском языке чаще всего существуют аналоги этих терминов, мы, тем не менее, предпочитаем им «оригиналы». Почему? Только ли потому, что так «удобнее»? Или потому что таким образом нам проще интегрироваться в мировое «информационное пространство»? Отчасти. Однако не только поэтому.

Анализ способов использования (прежде всего в русскоязычной литературе) термина «концепт» позволил нам предположить, что наша склонность пользоваться терминами, заимствованными из иностранных языков, коренится в неком механизме работы мышления. Описать этот механизм - основная цель данной статьи.

Употребление термина «концепт» в русскоязычной научной и философской литературе также вывело нас на другую важную проблему, суть которой состоит в следующем: использование в том или ином научном сообществе иностранных терминов может приводить к тому, что с этими терминами начинают связывать значения, которые в «родной» для них, этих терминов, среде с ними не связывались. Данная коллизия чаще всего возникает в результате действия упомянутого выше механизма.

Речь пойдет также о том, как термин «концепт» прижился на российской почве, и о том, каким образом он стал пониматься так, как понимается сегодня в отечественной философии и науке. Рассмотрение это позволит определить и способы решения обозначенной проблемы, и прояснить некоторые из тех общих принципов, в соответствии с которыми происходит заимствование иностранных терминов.

\section{Концепт в истории. Концепт в философии и науке}

Понятие концепта имеет многовековую историю [Демьянков, 2001; Демьянков, 2007]. Одно из ранних его появлений связано со средневековой полемикой об универсалиях (общих понятиях).

Средневековые схоласты восприняли от философов античности проблему, суть которой состояла в том, что считать истинной реальностью - общую идею вещи или саму вещь. Реалисты полагали, что первичны общие идеи, а не конкретные вещи; номиналистьл - что и род, и виды - просто слова, реальны же только обозначаемые ими конкретные вещи. Что касается третьего направления этого спора - конщептуализма, то устами своего провозвестника П. Абеляра оно утверждало, что универсалии (то есть общие понятия) действительно существуют, но только в уме (душе) человека [Неретина, 1994]. Причем именно как концептыл. Так, в разуме может существовать концепт (идея) дерева, соотнося вещь с которым разум решает, является ли она деревом. С одной стороны, дерево - это нечто большее, чем просто слово, звук с совершенно произвольным значением (как у номиналистов), а с другой - она не имеет иной реальности, кроме как через связь с конкретными вещами. То есть ее реальность чисто абстрактная, то есть концептуальная.

Как известно, и судьба самого П. Абеляра, и судьба его идей сложились печально. Он был осужден двумя церковными соборами, его имя и труды были преданы забвению.

В Новое время интерес к концепту как к некому объекту, схожему с понятием, но ему не тождественному, если и возникал, то эпизодически. Как указывают С.С. Неретина и 
А.П. Огурцов [2011], еще И. Канту было свойственно различение понятий и концептов, однако уже в посткантианской философии это различение все более и более стирается.

Ситуация начинает меняться в конце XIX - начале XX вв., когда термин «концепт» все более активно входит в философский оборот. Одним из первых, кто в XX в. заговорил о концепте, был русский религиозный философ С.А. Аскольдов (настоящая фамилия Алексеев). По С.А. Аскольдову, концепт - это «мысленное образование, которое замещает нам в процессе мысли неопределенное множество предметов одного и того же рода» [Аскольдов, 1928, с. 31]. Метафорически концепты были обозначены С.А. Аскольдовым как «почки сложнейших соцветий мысленных конкретностей» [Аскольдов, 1928, с. 34]. Концепты диалогичны, предполагают наличие связи между коммуникантами, порождают бесконечное разнообразие индивидуальных способов восприятия действительности и вследствие этого - бесконечное разнообразие вариантов смыслов [Олизько, 2014]. К сожалению, идеи С.А. Аскольдова на несколько десятилетий были забыты. В научный оборот их уже в постсоветское время ввел (точнее вернул) Д.С. Лихачев [Лихачев, 2015].

Оживлению внимания к феномену концепта в отечественной философии также способствовали попытки реконструкции концепта в его средневековом понимании. Лидером этого процесса следует считать С.С. Неретину.

С опорой на средневековые тексты С.С. Неретина предприняла попытку обосновать эквивокалистскую трактовку концепта. Согласно этой трактовке, концепт носит эквивокальный (двуосмысленный) характер, поскольку способен одновременно схватывать смысловую и словесную природы, связь вещи и речи, обращен как к человеку, так и к Богу [Неретина, 1994]. При этом концепт связывается с решением не только историкофилософских, но и эпистемологических задач.

Другая российская исследовательница Л.А. Микешина приходит к выводу, что гуманитарные науки в силу их наративистского характера оперируют не столько понятиями, сколько именно концептами [Микешина, 2002]. При этом под концептами понимаются «словообразы», которые не были доведены до кондиции абстрактных понятий и в силу того сохранили в себе многообразие смыслов и способность более полно, чем абстрактные понятия, отражать многообразие реальности.

Обратились к понятию концепта логика и аналитическая философия прежде всего в связи с такими значимыми для них проблемами, как концептуальный анализ и проблема концептуальных каркасов [Филатов, Михайловский и др., 2009, с. 161].

Важное направление актуализации понятия концепта связано с исследованиями, находящимися на границе философии и лингвокультурологии. Одним из идеологов этого направления был Ю.С. Степанов. Его понимание отношений между понятием и концептом состояло в том, что в то время как понятия мыслятся (являются объектами мышления), концепты не только мыслятся, но и переживаются [Степанов, 2010]. Трактовка концепта, предложенная Ю.С. Степановым, безусловно, эмотивистская [Неретина, Огурцов, 2011], однако сфера ее применимости не ограничивается лингвокультурологией, но распространяется и на эпистемологию. Любое знание предполагает некоторое переживание, некий эмоциональный компонент. Мысль способна порождать эмоцию, а эмоция способна служить импульсом к генерированию нового знания. В этом плане трактовка концепта, предложенная Ю.С. Степановым, может использоваться для решения именно эпистемологических задач.

Посструктуралистская философия объяснила понятие «концепт» иначе. Сошлемся в этой связи на книгу Ж. Делеза и Ф. Гваттари «Что такое философия?» [2009], один из наиболее явных посылов которой состоял в том, что философия есть творчество концептов. Менее явный, вытекающий из контекста и прямо не сформулированный (но, пожалуй, не менее важный, чем первый) посыл состоял в том, что концепты - это не вполне понятия (или не вполне традиционные понятия). Именно поэтому русский переводчик и перевел французское «le concept» как концепт, а не как понятие [Зенкин, 2009; Неретина, Огурцов 2011, 183]. 
Обращение к концептам произошло не только в философии, но и в конкретных науках. Ни в коей мере не претендуя на полноту, попробуем в самых общих чертах обозреть трактовки концепта в тех науках, в которых такое использование приобрело довольно устойчивый характер. Вместе с тем будем учитывать, что в научном знании разброс значений термина «концепт», пожалуй, еще более значителен, чем в философии, что, разумеется, не может не проблематизировать такой обзор.

Частично в обзоре мы будем следовать статье В.А. Ефремова [2009].

В когнитивных науках концепт понимается как базовая единица ментальных или вообще психических ресурсов сознания, связанных с познавательными процессами в широком их понимании. В когнитивных науках концепт стал своего рода «метапонятием» для самых разных когнитивных объектов, включая слова, образы, схемы и т.п.

Эпистемологический смысл когнитивистского понимания концептов обусловлен тем, что мышление и творчество следует рассматривать не как «простое оперирование абстрактными категориями (понятиями)», а как нечто, задействующее «более широкий спектр когнитивных возможностей человека», включая дорефлексивный опыт, религиозные представления, интуицию, предрассудки и т.п. [Филатова, 2007, с. 13].

Психолингвистика трактует концепт как базовое перцептивно-когнитивноаффективное образование, динамика которого обусловлена закономерностями психической реальности человека. Концепт в такой трактовке не сводится к лингвистическому измерению, но, например, включает в себя и то, что связано со зрительными, слуховыми, вкусовыми и прочими квалитативными элементами человеческой психики (то есть элементами, в полной мере в языке невыразимыми).

В лингвистических исследованиях концепт уподобляют представлению, наивному понятию, хотя и не отождествляют с ними, в том числе полагая, что концепт в существенной мере репрезентирует ассоциативное поле связываемого с ним слова. Довольно удачно концепт в подобном его понимании может быть смоделирован с помощью «полевой модели», предполагающей наличие у концепта как некоторого семантического поля своеобразных ядра и нескольких поясов периферии [Масалова, 2007]. Соответствующая такому пониманию «полевая модель» в той или иной мере отвечает трактовке концепта как нечеткого и текучего семантического объекта.

На стыке лингвистики и культурологии возникло лингвокультурологическое понимание концепта. Выступая в роли «базовой эвристической единицы» лингвокультурологии [Воркачев, 2012, 4], концепт среди прочего позволяет обращаться к осмыслению этнических и национальных культур, субкультур и т.п. В этой связи используется «слоевая модель» концепта, в рамках которой разные слои концепта являются конденсатом культурной жизни разных эпох [Масалова, 2007, с. 23].

С.Г. Воркачев отмечает: «Концепт - синтезирующее лингвоментальное образование, методологически пришедшее на смену представлению (образу), понятию и значению и включившее их в себя в "снятом", редуцированном виде - своего рода "гипероним" последних. В качестве "законного наследника" этих семиотических категорий лингвоконцепт характеризуется гетерогенностью и многопризнаковостью, принимая от понятия дискурсивность представления смысла, от образа - метафоричность и эмотивность этого представления, а от значения - включенность его имени в лексическую систему языка» [Лингвокультурный концепт..., 2007, с. 5].

Концепт как бы оказывается синтетическим и вместе с тем «семейным» понятием; его многоликость превращает его в некое общее ментальное образование, обращение к которому позволяет решать определенный круг проблем, возникающих в пределах различных отраслей научного знания. Недаром С.Г. Воркачев отмечает, что «концепт - это "многомерное идеализированное формообразование"..., однако единства мнений относительно числа семантических параметров, по которым может вестись его изучение, у концептологов нет: сюда включаются как понятийное, так и образное, ценностное, поведенческое, 
этимологическое и культурное "измерения"..., из которых почти каждое может иметь приоритетный статус в исследовании» [Воркачев, 2004, с. 6].

В политологии возникло направление, получившее название политической концептологии. Среди ее задач - метатеоретический анализ ключевых политических концептов (таких как политика, власть, свобода, государство, суверенитет, республика, демократия, революция и т.п.) [Макаренко, 2009]. Концепт при этом рассматривается как «продукт возвышенного ума (духа), который способен творчески воспроизводить и собирать смыслы» [Макаренко, 2009, с. 84]. Концепт - это в каком-то смысле прообраз понятия, его зачаток [Демьянков, 2007; Макаренко, 2009; Филатов, Михайловский, Никифоров, Игнатенко 2009]; в отличие от понятия концепт не ограничивает разнообразные смыслы, а напротив, конщентрирует их в себе.

В социологии концепт используется при построении программы социологических исследований. Существенное внимание при этом отводится процедурам интерпретации и операционализации концептов социологического исследования. Благодаря этому на уровне методологического блока программы исследования обеспечивается взаимоувязка качественной и количественной тактик видения социальной действительности, а также реалистической и номиналистической познавательных установок.

Необходимость в такой взаимоувязке возникает в связи с тем, что социолога интересует объективное, эмпирически обоснованное и количественно определенное знание, тогда как лежащие в основаниях любого нетривиального социологического исследования концепты напрямую, как правило, неизмеримы.

Как видим, понятие концепта сегодня широко распространено в современной отечественной философии и науке. Вместе с тем это не означает, что использование этого понятия не таит под собой определенных проблем. К обсуждению одной из таких проблем теперь и переходим. Маскируясь под проблему чисто лингвистическую, она на самом деле является методологической.

\section{Проблема перевода}

В современной западной (в основном - англоязычной, но также и на других европейских языках) философской и научной литературе аналог нашего термина «понятия» - это «concept» ${ }^{1}$. Синонимичный ему «notion» используется гораздо реже, причем скорее в значении идеи, представления, чем собственно логического понятия.

В связи с этим возникают следующие вопросы.

Не является ли видение феномена концепта, которое так или иначе «навязывается» приведенным выше обзором, неким чисто русским видением (соответственно, обзор этот слишком тенденциозным)? То есть не вкладываем ли мы, русскоязычные, в нашу трактовку концепта - в связи с анализом западных философских текстов - тот смысл, которого там изначально не было ${ }^{2}$ Можно ли тогда говорить, что в западной философской традиции существует артикуляция той проблематики, которую мы рассматриваем в этой статье? Наконец, учитывая все вышесказанное, можно ли приведенный обзор вообще воспринимать всерьез?

Возможно, что все те смыслы, которыми мы «нагружаем» понятие концепта, переводя западные источники или устраивая их разбор, на самом деле изначально (то есть, в текстах англоязычных и других иноязычных авторов) либо в нем вообще отсутствуют, либо входят как оттенки, не конденсируясь в отдельное понятие (то есть, тогда как мы можем разводить разные смыслы по отдельным понятиям, закреплять их с помощью разных тер-

\footnotetext{
${ }^{1}$ См. обзор в [Демьянков 2001].
}

2 «Пика употребительности в русском языке концепт достиг, когда этот термин начали употреблять в значении ином, чем просто "понятие", особенно в гуманитарных науках» [Демьянков 2007: 616]. 
минов - понятие и концепт - в западной литературе эти смыслы прекрасно «уживаются» под «крышей» одного - концепта).

Иначе говоря, не является ли проблема концепта (как она здесь формулируется) чисто русской проблемой? Не в том плане, что ни для кого больше она не может стать актуальной или хотя бы понятной, а в том, что впервые она в более или менее четком виде формулируется именно в России, русскоязычными философами и учеными (а потом задним числом приписывается западным источникам)?

Мы видим решение этой проблемы, которую условно можно назвать проблемой перевода, следующими путями.

Самый простой путь - приведенные сомнения можно просто отмести на том основании, что если показана актуальность некой философской проблемы, если показано, что такая проблема действительно существует, то не имеет никакого значения, как философ, ее сформулировавший, на нее вышел. Пусть даже это произошло в результате недоразумения или недостаточного владения иностранными языками. Естественно, если мы здесь имеем именно этот случай, то, вероятно, следует признать, что приведенный выше обзор не имеет особого смысла - хотя основная проблема данной статьи, пожалуй, смысл все-таки при этом сохранит.

Однако, как нам кажется, прибегать к столь радикальному варианту нет необходимости, ибо существует еще один путь, путь достаточно часто используемый и обычно рассматриваемый как вполне легитимный. Мы, разумеется, говорим об учете контекста. Да, в текстах, написанных на многих европейских языках, термины «понятие» и «концепт» не разводятся так, как это сделано в данной статье и во многих других русскоязычных работах, однако характер проблем, рассматриваемых в этих текстах, контекст, в котором употребляется термин «концепт», позволяют заключить, что такое разведение можно было бы считать уместным ${ }^{1}$.

На этом, пожалуй, можно было бы пока остановиться, однако мы сочли возможным пойти несколько дальше. А именно - мы хотим рассмотреть некий механизм функционирования сознания, важный, на наш взгляд, для понимания того, что произошло с термином «концепт» в России. Рассмотрение это, возможно, также будет способствовать выработке нового философского метода.

Итак, почему мы склонны использовать иностранные слова? Отчасти, видимо, чтобы продемонстрировать, что мы их знаем. Но не только. Гораздо интереснее другая причина. Она состоит в том, что в иностранные слова мы неосознанно вкладываем больше смысла, содержания, чем в их аналоги из собственного языка. Механизм тут довольно прост.

Когда мы изучаем иностранные слова, нам обычно предоставляется не одно значение этого слова, а несколько синонимичных. Например, как в случае с термином «понятие». Русско-английский словарь нам предложит не один английский его вариант, например, «concept», но и «notion», и «idea», и много еще. Аналогично в англо-русском словаре термину «concept» будет соответствовать и «понятие», и «концепт», и «идея», и «мысль» и прочее. Таким образом в нашем сознании одно иностранное слово будет ассоциироваться с несколькими «нашими» словами-синонимами (а может, и не совсем синонимами - ведь,

${ }^{1}$ Напомним, что термин «concept» имеет латинское происхождение, а не древнегреческое (хотя тот же Абеляр выводит свой концепт, анализируя труды Аристотеля), и что он появляется в Средние века. Хотя мы в конце концов и стали переводить его чаще всего как «понятие», то есть, точно так же, как древнегреческие термины, использовавшиеся Платоном и Аристотелем при сходных, как нам кажется, обстоятельствах, это вовсе не означает, что средневековый «сoncept» можно возводить к этим терминам, что он значит примерно то же самое, что и они, и что он, этот средневековый «concept» - это наше сегодняшнее «понятие» или даже «concept» современной англоязычной литературы. 
по большому счету, «идея» и «понятие» - это далеко не одно и тоже). И вот здесь-то и начинается самое интересное.

Часто бывает так, что для того, чтобы выразить ту или иную мысль, нам необходимо несколько сходных по значению слов (например, для характеристики чего-то нам бы хотелось использовать и слово «идея», и «понятие», и «мысль», и «представление» - просто потому, что мы чувствуем, что с помощью только одного из этих слов все оттенки нашей мысли не передать). Но перечислять все эти слова долго. К тому же, даже перечислив их, мы, возможно, будем чувствовать, что всего таким образом все равно не сказали. И тут у нас в памяти всплывает иностранное слово, которое, как мы помним из словаря, может переводиться и как «идея», и как «мысль», и как «представление» и как много что ещче из той же области (это «много что еще» особенно важно, поскольку позволяет помыслить в этом слове даже то, для чего у нас слов вообще нет). Его-то, это иностранное слово, мы и используем, чтобы передать нашу мысль - причем во всей ее, как нам кажется, полноте. То есть, можно сказать, что использование иностранных слов - это, с одной стороны, вопрос экономии (например, средств выражения), а с другой - средство передачи того, что иным способом вообще нельзя было бы передать.

Естественно, так, то есть «во всей полноте» - это чаще только наше, субъективное, ощущение. Другие - прежде всего иностранцы, для которых это слово родное, - так могут и не чувствовать, ведь у них оно, скорее всего, имеет только одно основное значение (по крайней мере, не столько значений, сколько с ним ассоциируется у нас).

Думается, приведенное только что рассуждение может снять многие проблемы, в том числе связанные с толкованием таких понятий, как логос или эйдос.

Однако что же оно, это рассуждение, дает для нашей темы? Очевидно, многое. Ведь поскольку термин «концепт» для нас не «родной», мы, в соответствии с описанным механизмом, во многих случаях вполне можем связывать с ним гораздо больше смысла, значений, нюансов и прочего, чем те ученые и философы, для которых это слово - слово родного им языка.

Поскольку речь идет о философии, то есть той сфере, где многозначность, неопределенность, многосмысленность - дело совершенно обычное, мы оказываемся в более выгодной ситуации, чем, к примеру, англичане, поскольку мы с помощью слова «концепт» можем выразить гораздо больше, чем они - правда это «гораздо больше» будет только для нас. Для них, скорее всего, придется делать, так сказать, «обратный перевод» соответствующего термина - перевод, в который понадобится «втиснуть» все те значения, которые мы придали этому термину по собственному почину (или, несколько иначе, переопределить удельный вес смыслов, связываемых с этим словом в том языке, из которого это слово пришло) ${ }^{1}$.

\section{Резюме}

Выше мы кратко рассмотрели историю использования понятия концепта в философской и научной литературе от времен Средневековья до наших дней.

Мы предположили, что в отечественной русскоязычной литературе данное понятие может иметь несколько иной смысл, чем в иностранной литературе на тех европейских языках, из которых оно было заимствовано (причем этот смысл, как правило, выявляется через противопоставление концепта понятию).

Данная ситуация обусловлена действием некоего психологического механизма, активизирующегося тогда, когда мы имеем дело с иностранными словами. Не вдаваясь в детали, суть его действия состоит в том, что практически любое иностранное слово, когда мы его заучиваем, заучивается не с одним основным значением, а с несколькими близкими. Например, «concept» - это и «понятие», и «идея», и «представление», и много что еще.

${ }^{1}$ В иностранной литературе термином «concept» обычно просто пользуются, в нашей же его еще и толкуют. 
При этом в странах, для языков которых данное слово является «родным», оно чаще всего имеет как раз только одно основное значение.

Поскольку это слово для нас не «родное», мы чувствуем меньшее давление традиции, употребляя его. Если сюда еще приплюсовать обилие синонимов (или даже «квази-синонимов»), с которыми оно у нас ассоциируется, то результатом часто будет то, что смысл этого слова в нашей литературе будет существенно отличаться от смысла этого слова в литературе на том языке, из которого оно было заимствовано.

По-другому: иностранное слово выступает не просто в качестве аналога (перевода) слова, имеющего ряд синонимов (или просто в чем-то близких слов) в родном нам языке, то есть тоже в качестве чего-то вроде их синонима, а в качестве слова-заменителя всех этих слов. В понятие, обозначенное иностранным словом, мы таким образом вкладываем все те смыслы, которые мы связываем со всеми этими словами. То есть, по сути, создаем принципиально новое понятие, которого не было ни в родном нам, ни в иностранном языке.

Этот механизм совсем не обязательно должен рассматриваться как проблема. Наоборот, осознание его существования и действия позволяет обогатить аппарат науки и философии. Правда в этом случае, вероятно, понадобится делать «обратный перевод» терминов, подвергшихся действию данного механизма, перевод, который бы позволил донести до иностранного читателя те смыслы, которые либо остаются неактуализированными, четко не артикулированными, либо не связываются со специальным термином в «родной» (для термина) литературе.

\section{Список литературы}

1. Аскольдов С.А. 1928. Концепт и слово. В кн.: Русская речь. Вып. II. Ленинград: Academia: 28-44.

2. Воркачев С.Г. 2004. Счастье как лингвокультурный концепт. М., ИТДГК «Гнозис», 192 с.

3. Воркачев С.Г. 2012. Anglica selecta: избранные работы по лингвоконцептологии. Волгоград, Парадигма, 205 с.

4. Делез Ж., Гваттари Ф. 2009. Что такое философия? М., Академический Проект, 261 с. (Deleuze G., Guattari F. Qu'est-ce que la philosophie? Paris, Minuit, coll. «Critique», 1991, 206.).

5. Демьянков В.3. 2001. Понятие и концепт в художественной литературе и в научном языке. Вопросы филологии, 1: 35-47.

6. Демьянков В.3. 2007. Термин «концепт» как элемент терминологической культуры.

В кн.: Язык как материя смысла. Сборник статей в честь академика Н.Ю. Шведовой. М., Азбуковник: 606-622.

7. Ефремов В.А. 2009. Теория концепта и концептуальное пространство. Известия Российского государственного педагогического университета им. А.И. Герцена, 104: 96-106.

8. Зенкин С. 2009. Послесловие переводчика. В кн.: Делез Ж., Гваттари Ф. Что такое философия? М., Академический Проект: 254-260.

9. Лингвокультурный концепт: Типология и области бытования. 2007. Волгоград, ВолГУ, $400 \mathrm{c}$.

10. Лихачев Д.С. 2015. Концептосфера русского языка. В кн.: Лихачев Д.С. Избранные труды по русской и мировой культуре. СПб., СПбГУП: 240-251.

11. Макаренко В.П. 2009. Политическая концептология: первые итоги разработки. Политическая концептология, 1: 79-116.

12. Масалова С.И. 2007. Философские концепты как регулятивы гибкой рациональности: Трансформация от античности до Нового времени. Автореф. дис. ... д-ра филос. наук. Ростов-наДону, 47.

13. Микешина Л.А. 2002. Философия познания. Полемические главы. М., ПрогрессТрадиция, $624 \mathrm{c}$.

14. Неретина С.С. 1994. Слово и текст в средневековой культуре. Концептуализм Абеляра. М., Гнозис, 216 с.

15. Неретина С.С., Огурцов А.П. 2011. Концепты политической культуры. М., ИФРАН, 279 с. 
16. Олизько Н.С. 2014. Концептуальное фрактальное моделирование. Вестник Челябинского государственного университета. Серия «Филология. Искусствоведение», 335 (6), $158-161$.

17. Петруня О.Э. 2012. Сергей Алексеевич Аскольдов: Несостоявшаяся революция в теории познания. В кн.: Аскольдов С.А. Гносеология. Статьи. М., Изд-во Московской Патриархии Русской Православной Церкви: 3-37.

18. Степанов Ю.С. 2010. Мыслящий тростник. Книга о «Воображаемой словесности». Калуга, Эйдос, 168 с.

19. Филатов В.П., Михайловский А.В., Никифоров А.Л., Игнатенко А.С. 2009. Обсуждаем статью «Концепт». Эпистемология \& философия науки, 22 (4): 161-170.

20. Филатова А.А. 2007. Концепт как конституирующий элемент культуры (когнитивный подход). Автореф. дис. ... канд. филос. наук. Ростов-на-Дону, 27 с.

\section{Reference}

1. Askol'dov S.A. 1928. Koncept i slovo. In: Russkaja rech' [Russian speech]. Vyp. II. Leningrad: Academia: 28-44.

2. Vorkachev S.G. 2004. Schast'e kak lingvokul'turnyj concept [Happiness as a linguistic and cultural concept]. M., ITDGK «Gnozis», $192 \mathrm{c}$.

3. Vorkachev S.G. 2012. Anglica selecta: izbrannye raboty po lingvokonceptologii [Anglica selecta: Selected works on linguoconceptology]. Volgograd, Paradigma, $205 \mathrm{p}$.

4. Delez Zh., Gvattari F. 2009. Chto takoe filosofija? [What is philosophy?] M.: Akademicheskij Proekt: 261 p. (Deleuze G., Guattari F. Qu'est-ce que la philosophie? Paris, Minuit, coll. «Critique», 1991, 206 p.).

5. Dem'jankov V.Z. 2001. Ponjatie i koncept v hudozhestvennoj literature i v nauchnom jazyke. [Concept and concept in fiction and in scientific language]. Voprosy filologii, 1: 35-47.

6. Dem'jankov V.Z. 2007. Termin «koncept» kak jelement terminologicheskoj kul'tury. [The term "concept" as an element of terminological culture]. In: Jazyk kak materija smysla: sbornik statej v chest' akademika N.Ju. Shvedovoj. [Language as the matter of meaning. Collection of articles in honor of academician N. Yu. Shvedova]. M., Azbukovnik: 606-622.

7. Efremov V.A. 2009. Teorija koncepta i konceptual'noe prostranstvo. [The theory of the concept and conceptual space]. Izvestija Rossijskogo gosudarstvennogo pedagogicheskogo universiteta im. A.I. Gercena, 104: 96-106.

8. Zenkin S. 2009. Posleslovie perevodchika. In: Delez Zh., Gvattari F. Chto takoe filosofija? [Qu'est-ce que la philosophie?] M., Akademicheskij Proekt: 254-260.

9. Lingvokul'turnyj koncept: Tipologija i oblasti bytovanija [Linguocultural concept: typologies and areas of life]. Volgograd, VolGU, $400 \mathrm{p}$.

10. Lihachev D.S. 2015. Konceptosfera russkogo jazyka. In: Lihachev D.S. Izbrannye trudy po russkoj i mirovoj kul'ture [Selected Works on Russian and World Culture]. SPb., SPbGUP: 240-251.

11. Makarenko V.P. Politicheskaja konceptologija: pervye itogi razrabotki. [Political conceptology: first results of development]. Politicheskaja konceptologija, 1: 79-116.

12. Masalova S.I. 2007. Filosofskie koncepty kak reguljativy gibkoj racional'nosti: Transformacija ot antichnosti do Novogo vremeni [Philosophical Concepts as Regulators of Flexible Rationality: Transformation from Antiquity to the New Age]. Abstract. dis. ... d-ra filos. nauk. Rostov-naDonu, $47 \mathrm{p}$.

13. Mikeshina L.A. 2002. Filosofija poznanija. Polemicheskie glavy [The philosophy of knowledge. Polemic chapters]. M., Progress-Tradicija, 624 p.

14. Neretina S.S. 1994. Slovo i tekst v srednevekovoj kul'ture. Konceptualizm Abeljara [Word and text in medieval culture. Abelard Conceptualism]. M., Gnozis, 216 p.

15. Neretina S.S., Ogurcov A.P. 2011. Koncepty politicheskoj kul'tury [Political Culture Concepts]. M., IFRAN, $279 \mathrm{p}$.

16. Oliz'ko N.S. 2014. Konceptual'noe fraktal'noe modelirovanie. [Conceptual fractal modeling]. Vestnik Cheljabinskogo gosudarstvennogo universiteta. Serija «Filologija. Iskusstvovedenie», 335 (6): $158-161$.

17. Petrunja O.Je. 2012. Sergej Alekseevich Askol'dov: Nesostojavshajasja revoljucija v teorii poznanija. [Sergey Askold: the Failed revolution in the theory of knowledge]. In: Askol'dov 
S.A. Gnoseologija. Stat'I [Epistemology. Articles]. - M., Izd-vo Moskovskoj Patriarhii Russkoj Pravoslavnoj Cerkvi: 3-37.

18. Stepanov Ju.S. 2010. Mysljashhij trostnik. Kniga o «Voobrazhaemoj slovesnosti» [Thinking reed. Book of «Imaginary Literature»]. Kaluga, Jejdos, 168 p. (in Russian)

19. Filatov V.P., Mihajlovskij A.V., Nikiforov A.L., Ignatenko A.S. 2009. Obsuzhdaem stat'ju «Koncept». [Discussing the article "Concept"]. Jepistemologija \& filosofija nauki, 22 (4): 161-170.

20. Filatova A.A. 2007. Koncept kak konstituirujushhij jelement kul'tury (kognitivnyj podhod) [Concept as a constitutive element of culture (cognitive approach)]. Abstract. dis. ... kand. filos. nauk. Rostov-na-Donu, 27 p.

\section{Ссылка для цитирования статьи For citation}

Швырков А.И., Кошлаков Д.М. 2020. Концепт и проблема перевода. NOMOTHETIKA: Философия. Социология. Право. 45 (1): 59-68. DOI 10.18413/2712-746X-2020-45-1-59-68

Shvyrkov A.I., Koshlakov D.M. 2020. Concept and the problem of translation. NOMOTHETIKA: Philosophy. Sociology. Law.45 (1): 59-68. (in Russian).

DOI 10.18413/2712-746X-2020-45-1-59-68 